\title{
Gamma Deficits as a Neural Signature of Cognitive Impairment in Children Treated for Brain Tumors
}

\author{
(1)Colleen Dockstader, Frank Wang, Eric Bouffet, and Donald J. Mabbott \\ The Hospital for Sick Children, Toronto, Ontario M5G 1X8, Canada
}

\begin{abstract}
Cognitive impairment is consistently reported in children treated for brain tumors, particularly in the categories of processing speed, memory, and attention. Although tumor site, hydrocephalus, chemotherapy, and cranial radiation therapy (CRT) are all associated with poorer function, CRT predicts the greatest deficits. There is a particularly high correlation between CRT and slowed informationprocessing speed. Cortical gamma-band oscillations have been associated with processing behaviorally relevant information; however, their role in the maintenance of cognition in individuals with processing deficits is unclear. We examined gamma oscillations using magnetoencephalography (MEG) in children undergoing CRT to test whether gamma characteristics can be a signature of cognitive impairment in this population. We collected resting-state data as well as data from baseline and active periods during two visual-motor reaction time tasks of varying cognitive loads from 18 healthy children and 20 patients. We found that only high-gamma oscillations $(60-100 \mathrm{~Hz})$, and not low-gamma oscillations $(30-59 \mathrm{~Hz})$, showed significant group differences in absolute power levels. Overall, compared with healthy children, patients showed the following: (1) lower total high-gamma (60-100 Hz) power during the resting state, as well as during task-related baseline and performance measures; (2) no change in gamma reactivity to increases in cognitive load; and (3) slower processing speeds both inside and outside MEG. Our findings show that high-gamma oscillations are disrupted in children after treatment for a brain tumor. The temporal dynamic of the high-gamma response during information processing may index cognitive impairment in humans with neurological injury.
\end{abstract}

Key words: brain tumor; children; cranial radiation therapy; gamma oscillations; magnetoencephalography; visual-motor

\section{Introduction}

Much has been made about the promise of using neuroimaging markers to measure the nature, extent, and prognosis of cognitive impairment in the injured brain (Greicius, 2008; Broyd et al., 2009; Colonnese and Khazipov, 2012). However, the neural mechanisms of impaired information processing, a core deficit after many forms of brain injury (Anderson and Arciniegas, 2010; Dockree and Robertson, 2011; Padovani et al., 2012; Taylor, 2012), are unclear. We propose that gamma oscillations may be an excellent marker of cognitive health and impairment in children.

The rhythmic firing of groups of neurons produces cortical oscillations that can be characterized by their latency and power at specific frequencies. Changes in these characteristics are observed in response to external stimuli or internal processes.

\footnotetext{
Received Dec. 13, 2013; revised May 12, 2014; accepted May 18, 2014.

Author contributions: C.D. and D.J.M. designed research; C.D. performed research; F.W. contributed unpublished reagents/analytic tools; C.D., F.W., and D.J.M. analyzed data; C.D., E.B., and D.J.M. wrote the paper.

This research was supported by operating grants from by the Canadian Institutes of Health Research, the Pediatric Oncology Group of Ontario, and the Garron Family Cancer Centre at the Hospital for Sick Children. We thank Dr. Doug Cheyne for providing Brainwave software, and Dr. Suresh Muthukumaraswamy for providing the visual stimulus. We also thank Marc Lalancette for developing our head motion analysis software. In addition, we thank Drs. Michael Salter and Sam Doesburg for reviewing earlier versions of the manuscript.

The authors declare no competing financial interests.

Correspondence should be addressed to Dr. Colleen Dockstader, Paediatric Brain Tumour Program, Division of Haematology/Oncology, and Department of Psychology, The Hospital for Sick Children, 686 Bay Street, 8th floor, Toronto, 0N M5G 0A4, Canada. E-mail: colleen.dockstader@sickkids.ca.

DOI:10.1523/JNEUROSCI.5220-13.2014

Copyright $\odot 2014$ the authors $\quad 0270-6474 / 14 / 348813-12 \$ 15.00 / 0$
}

Gamma oscillations $(30-100 \mathrm{~Hz})$ are particularly associated with cognitive function, as follows: increases in gamma power correlate with faster reaction times (Jokeit and Makeig, 1994; Schadow et al., 2009) and enhanced response accuracy (Kaiser et al., 2009); gamma latencies correlate with cognitive performance (Jokeit and Makeig, 1994; Haig et al., 2000; Martinovic et al., 2007; Schadow et al., 2009); and gamma power increases during attention (Müller et al., 2000), learning (Miltner et al., 1999), and memory (Tallon-Baudry et al., 1998; Lutzenberger et al., 2002) processes, as well as during increased cognitive demand (Mainy et al., 2007; Gaetz et al., 2013).

Cognitive deficits are consistently reported in children treated for brain tumors (Mulhern et al., 1999; Reddick et al., 2003; Merchant et al., 2005, 2009; Mabbott et al., 2006; Liu et al., 2007). Of tumor and treatment variables, cranial radiation therapy (CRT) is most predictive of the severity of these deficits (Askins and Moore, 2008; Winick, 2011). Children treated for brain tumors, including CRT, show slower stimulus response times (Schatz et al., 2000a); delayed motor responses (Berger et al., 2005; Mahone et al., 2007); and deficits in attention, learning, and memory (Mabbott et al., 2008, 2009; Riggs et al., 2014). Furthermore, these children demonstrate slower neural processing speeds and irregular cortical activations in EEGs (Uberall et al., 1996) and functional abnormalities in fMRI (Zou et al., 2005). As such, these children are an excellent population in which to test the critical role of gamma power in cognitive impairment following brain injury. 
We recently reported greater relative gamma reactivity in visual and motor regions and corresponding slowed reaction times during simple visual-motor task performance in children undergoing CRT for brain tumors than healthy children (Dockstader et al., 2013). Relative gamma increases in patients could reflect compensation for an inherent gamma deficit where relatively greater gamma was required for task performance. Alternatively, this population could exhibit abnormally high gamma levels that interfere with efficient task performance. To better understand the nature of the gamma dynamic in these patients, we measured absolute gamma power levels in the resting state and during task performance in two tasks of varying cognitive load. During task performance, we calculated absolute power during a baseline period before task initiation and the change in absolute power during the task-related active period. We argue that if children undergoing CRT have an overall gamma deficit that relates to cognitive function, then absolute gamma power should (1) be lower in patients in the resting state and during task performance, and (2) correlate with the proficiency of task performance.

\section{Materials and Methods \\ Participants}

Participants were 18 healthy children and 20 children undergoing CRT for pediatric brain tumors at The Hospital for Sick Children. Datasets from the lower cognitive load visual-motor task came from 15 patients and 17 control subjects in our previous study in which we showed group differences in relative gamma responses (Dockstader et al., 2013). Informed consent was obtained by all participants, and the study was approved by the hospital Research Ethics Board. All patients underwent CRT for the treatment of malignant tumors of the posterior fossa (PF) and were seen for $>12$ months following treatment. Late effects related to radiation typically begin to emerge during this time (Spiegler et al., 2004). Eligible patients were identified through database review, which included those patients in whom PF medulloblastoma or ependymoma had been diagnosed between 2001 and 2009. Patients were not recruited if they had a diffuse brainstem glioma, were receiving palliative care, or had a premorbid history of neurological/learning disability. Of the patients, 15 were treated for medulloblastoma, and 5 for ependymoma. All medulloblastoma patients were treated with surgery, chemotherapy, and cranial-spinal radiation with a boost to the PF. Ten patients with medulloblastoma were treated with reduced dose cranial-spinal radiation (i.e., $2340 \mathrm{cGy}$ ), and the remaining 5 patients received standard dose cranialspinal radiation (i.e., $3600 \mathrm{cGy}$ ). All five patients with ependymomas received focal radiation to the PF (5940 cGy), and one patient received adjuvant chemotherapy. Two patients with ependymomas showed recurrent disease, and subsequently received chemotherapy and standard dose cranial-spinal radiation ( $3600 \mathrm{cGy}$ ) with a boost to the surgical bed (5940 cGy). The mean ( \pm SD) ages of participants at the time of testing were as follows: in 18 healthy children, $136.1 \pm 41.49$ months; in 20 patients, $144.78 \pm 30.98$ months. There were no significant differences in age or sex between the control group (12 males and 6 females) and the patient group ( 13 males and 7 females; age: $t_{(36)}=0.71, p>0.05$; sex: $\mathrm{X} 2$ $(1, N=38)=0.012, p>0.05)$. All participants were right handed.

\section{Magnetoencephalography recordings}

Neuromagnetic activity was recorded using a whole-head 151 channel CTF MEG system located in a magnetically shielded room. Magnetoencephalography (MEG) data were collected continuously at a rate of 1200 samples/s and were filtered at $0.3-300 \mathrm{~Hz}$. Before MEG data acquisition, each patient was fitted with three fiducial localization coils placed at the nasion and preauricular points to localize the position of the patient's head relative to the MEG sensors. Participants lay supine in the MEG room, with their eyes open and fixated on a black cross $(2 \times 2 \mathrm{~cm})$ presented on a semitransparent screen placed $50 \mathrm{~cm}$ from subjects' eyes. Eyeblinks and saccades were monitored with electro-oculograms (EOGs) applied just distal to the lateral canthus of each eye, and one on the left mastoid process. Continuous head movement was monitored with a head-tracking system during data acquisition. An off-line system tracked motion artifacts in the following two ways: (1) where the current position deviated $5 \mathrm{~mm}$ from the reference position; and (2) when there was a 5 $\mathrm{mm}$ deviation within a single trial. Any trials in which head movement was $\geq 5 \mathrm{~mm}$ were also not included in any analysis (this ended up being $<1 \%$ of trials for either group). These parameters for detecting and correcting for motion artifact are widely accepted in the MEG pediatric literature (Xiang et al., 2013; Cheyne et al., 2014; Todd et al., 2014). After the removal of above-threshold data, we conducted a head motion analysis and determined that there were no group differences in head motion in any task, as measured by the average fiducial distance from the original head position across a task as well as the average head movement within each trial (all $p$ values were $>0.05$ ). Children were monitored through a camera and head movement/EOG/EMG activities displayed on a monitor outside the MEG room. The time points of overt saccades/blinks were marked and visually inspected at a later date. Trials were marked "bad" and removed before analysis for any that contained overt saccades/eye movements occurring from -200 to $0 \mathrm{~ms}$ before onset of the visual cue. Moreover, all participants received a brief $(\sim 20 \mathrm{~s})$ trial of each task to ensure that they understood instructions, could comfortably see the screen and the target stimuli, and could comfortably press the response button before data collection. One patient required corrective lenses for the task, and MEG-compatible lenses were made available. Upon completion of MEG data collection, the coils were replaced with MRI-visible markers for coregistration between MEG and MRI information.

\section{MEG tasks}

Resting state

Participants were instructed to lie still, keep their eyes open, and fixate on the cross for the duration of a 3 min recording.

\section{Visual-motor reaction time task}

Lower load task. During the task, participants' eyes were open and fixated on a black cross. Their dominant hand was resting at their side with their thumb gently resting on the button of a button box. Pseudo-randomly, every $1.5-2.5 \mathrm{~s}$ the black fixation cross was replaced with a green cross accompanied by a static visual contrast grating in the lower visual field. The location and dimensions of this contrast grating have been shown to elicit a strong visual evoked field $\sim 75 \mathrm{~ms}$ after stimulus onset (Koelewijn et al., 2011). Participants were instructed to push the button with their dominant thumb as soon as the green cross appeared. The time of the button press in response to the green cross was recorded as the "reaction time." Each participant underwent 100 trials.

Higher load task. This task was similar to the lower load task (LLT); however, every $1.5-2.5 \mathrm{~s}$ the black fixation cross was replaced with either a green cross or a red cross accompanied by a static visual contrast grating. Subjects were instructed to press the button as quickly as possible in response to the green cross and to do nothing in response to a red cross. The time of the button press in response to the green cross was recorded as the "reaction time." There were 197 green crosses and 100 red crosses presented pseudo-randomly. As stimulus discrimination and response selection was required, this task had a higher cognitive load than the lower load task. The presentation order of all tasks was counterbalanced across participants within each group (Fig. 1).

\section{Analyses}

\section{MEG analyses}

MEG data were digitally filtered off-line for low-gamma $(30-59 \mathrm{~Hz})$ and high-gamma $(60-100 \mathrm{~Hz})$. We divided gamma oscillations into lowfrequency and high-frequency bandwidths based on recent evidence that low $(<60 \mathrm{~Hz})$ and high $(\geq 60 \mathrm{~Hz})$ gamma-band responses can be dissociated during task performance (Brovelli et al., 2005; Sun et al., 2012; Grent-'t-Jong et al., 2013) and can be differentially affected in populations with cognitive deficits (Sun et al., 2012). Data were also filtered outside the gamma range to ask whether there were any group effects in other bandwidths, as follows: delta $(0.5-3 \mathrm{~Hz})$, theta $(4-7 \mathrm{~Hz})$, alpha $(8-12 \mathrm{~Hz})$, and beta $(13-29 \mathrm{~Hz})$. 


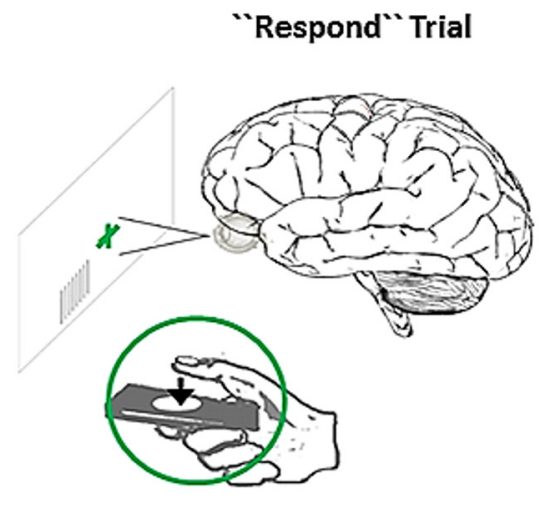

“Don't Respond"Trial

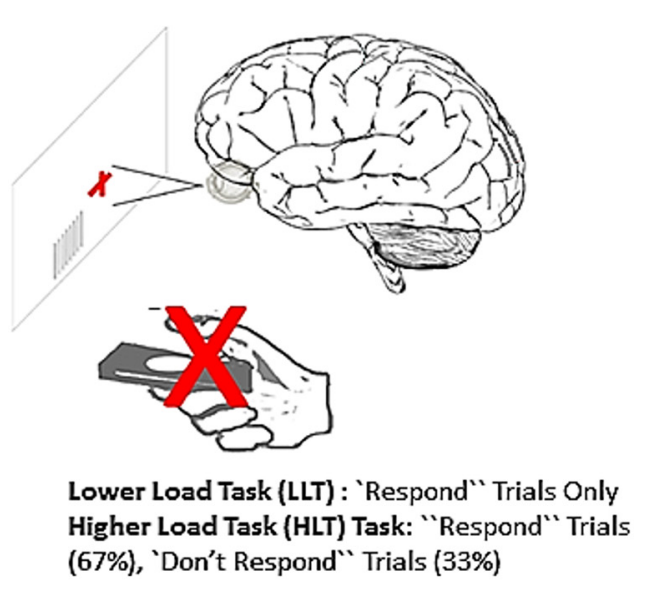

Figure 1. Participants performed two counterbalanced tasks in the MEG: visual-motor reaction-time LLTs and HLTs. In both tasks, participants were to attend to a visual stimulus and respond as quickly as possible when cued. Reaction time was recorded for each trial. Only "Respond" trials were presented for the LLT. For the HLT, Respond trials were presented on $67 \%$ of trials, and on $33 \%$ of trials a different cue was presented in which no response was required (i.e., "Don't Respond" trials). The HLT involves increase cognitive load versus the LLT, as stimulus discrimination is required. See also Table 1.

\section{Resting-state oscillations}

Average absolute power-or total power-across $120 \mathrm{~s}$ was calculated for a single trial from 30 to $150 \mathrm{~s}$ from the onset of the resting state for each channel, within each bandwidth, and across the whole brain (i.e., all channels), as well as regionally for each individual. In the latter, MEG channels were grouped into the following 10 distinct regions: bilateral frontal, temporal, parietal, occipital, and central (Fig. $2 A$ ). These regions were based on the work of Bosma et al. (2008). Topographic representations of the power spectrum were created in which each individual pixel on the topoplot represented the value of spectral power for the corresponding local MEG channel.

\section{Task-related oscillations}

Whole-brain oscillations (baseline and active periods). A baseline interval for each bandwidth was calculated as the time period just before the visual cue. The change in absolute power during the active period was then calculated by subtracting series of active windows (following the visual cue) from baseline. The changes in power were averaged across the whole-brain for both LLTs and higher load tasks (HLTs). The corresponding baseline/active time windows were applied: delta $(0.5-3 \mathrm{~Hz})$, baseline $-600 \mathrm{~ms}$ to $0 \mathrm{~ms}$, active time window 0 to $600 \mathrm{~ms}$ after visual cue); theta $(4-7 \mathrm{~Hz})$, baseline $-200 \mathrm{~ms}$ to $0 \mathrm{~ms}$, active time windows starting at $0-200 \mathrm{~ms}$ after visual cue and every $200 \mathrm{~ms}$ following; $\alpha(8-12$ $\mathrm{Hz}$ ), baseline $-100 \mathrm{~ms}$ to $0 \mathrm{~ms}$, time windows starting at $0-100 \mathrm{~ms}$ after visual cue and every $100 \mathrm{~ms}$ following; beta $(13-29 \mathrm{~Hz})$, baseline $-75 \mathrm{~ms}$ to $0 \mathrm{~ms}$, active time windows starting at $0-75 \mathrm{~ms}$ after visual cue and every $75 \mathrm{~ms}$ following; gamma (both low and high $30-100 \mathrm{~Hz}$ ), baseline $-30 \mathrm{~ms}$ to $0 \mathrm{~ms}$, active time windows starting at $0-30 \mathrm{~ms}$ after visual cue and every $30 \mathrm{~ms}$ following. These windows were corresponded to the number of oscillations of a particular frequency in $1000 \mathrm{~ms}$. Topographic representations of the power spectrum for each time window were then created.

Regional oscillations. Using only the bandwidth that showed significant differences in the whole-brain analysis $(60-100 \mathrm{~Hz})$, we applied the same analysis described above to each of the 10 topographic regions separately.

Beamformer source localization. Using only the bandwidth and time windows that showed significant group differences in the topographic, task-related analysis we applied a beamformer method across the entire brain to determine the exact locations of underlying neural generators observed during task performance for each group. Spatial localization was based on the synthetic aperture magnetometry (SAM) approach (Robinson and Vrba, 1999) and automatized through BrainWave software (developed by Dr. Douglas Cheyne, The Hospital for Sick Children, Toronto, ON, Canada). Therefore, data analysis was restricted to a period of $60-100 \mathrm{~Hz}$ during the significant active time windows with a baseline period of -30 to $0 \mathrm{~ms}$ relative to the visual cue. Images were spatially normalized and registered to a pediatric template (Wilke et al., 2002) using the BrainWave toolbox integrated with Statistical Parametric Mapping software (Wellcome Trust Centre for Neuroimaging, London, UK). A between-group permutation analysis of 512 replications that was thresholded at 0.05 was applied. Talaraich labels were obtained by warping the averaged data fit to a pediatric template to the adult MNI template (ICBM152; Mazziotta et al., 2001). Data were thresholded at a value of 0.1 (pseudo-Z). In particular, sources that corresponded to regional topographic differences were investigated.

Neuropsychological information processing speed scores. A composite index score for processing speed index (PSI) was calculated based on the processing speed subtests of the Wechsler Intelligence Scale for Children-fourth edition (WISC-IV; Wechsler, 2004). PSI scores were obtained for patients only (during a clinical visit) and within 6 months of MEG testing.

\section{Statistical approach}

Resting-state oscillations

A single value for each participant, within each frequency bandwidth, was derived from the averaged absolute power value across all topoplot pixels for each individual's resting-state data. A MANOVA was conducted on the mean absolute power across all six bandwidths with group (patient and control groups) as a between-subjects factor for the whole brain and, separately, for each region.

\section{Reaction time during task}

A repeated-measures ANOVA was conducted on the mean reaction time to the cue for the visual-motor tasks, with group (patient and control groups) as a between-subjects factor and task (LLT and HLT) as a withinsubjects factor.

\section{Task-related oscillations}

Active periods. Overall, we conducted a series of repeated-measures ANOVAs to test the effects of group, active time windows, and task on whole-brain frequency power and regional frequency power, respectively. For all analyses, significant main effects and lower-order interactions were interpreted in the context of the highest-order interaction that was significant: tests of simple effects—corrected for multiple comparisons (Bonferroni correction) to address type 1 errors-were then used to interrogate the highest-order interaction.

Whole-brain oscillations. First, we examined group differences in the time course of changes in absolute oscillatory power during the visualmotor LLTs and HLTs across the whole brain for each bandwidth separately. Separate repeated-measures ANOVAs were conducted on mean absolute power for each bandwidth with group (patient and healthy children groups) as a between-subjects factor, and task (LLT and HLT) and time (active time window) as within-subjects factors. Investigation of temporal changes continued up to $600 \mathrm{~ms}$ after the visual cue as the 
B
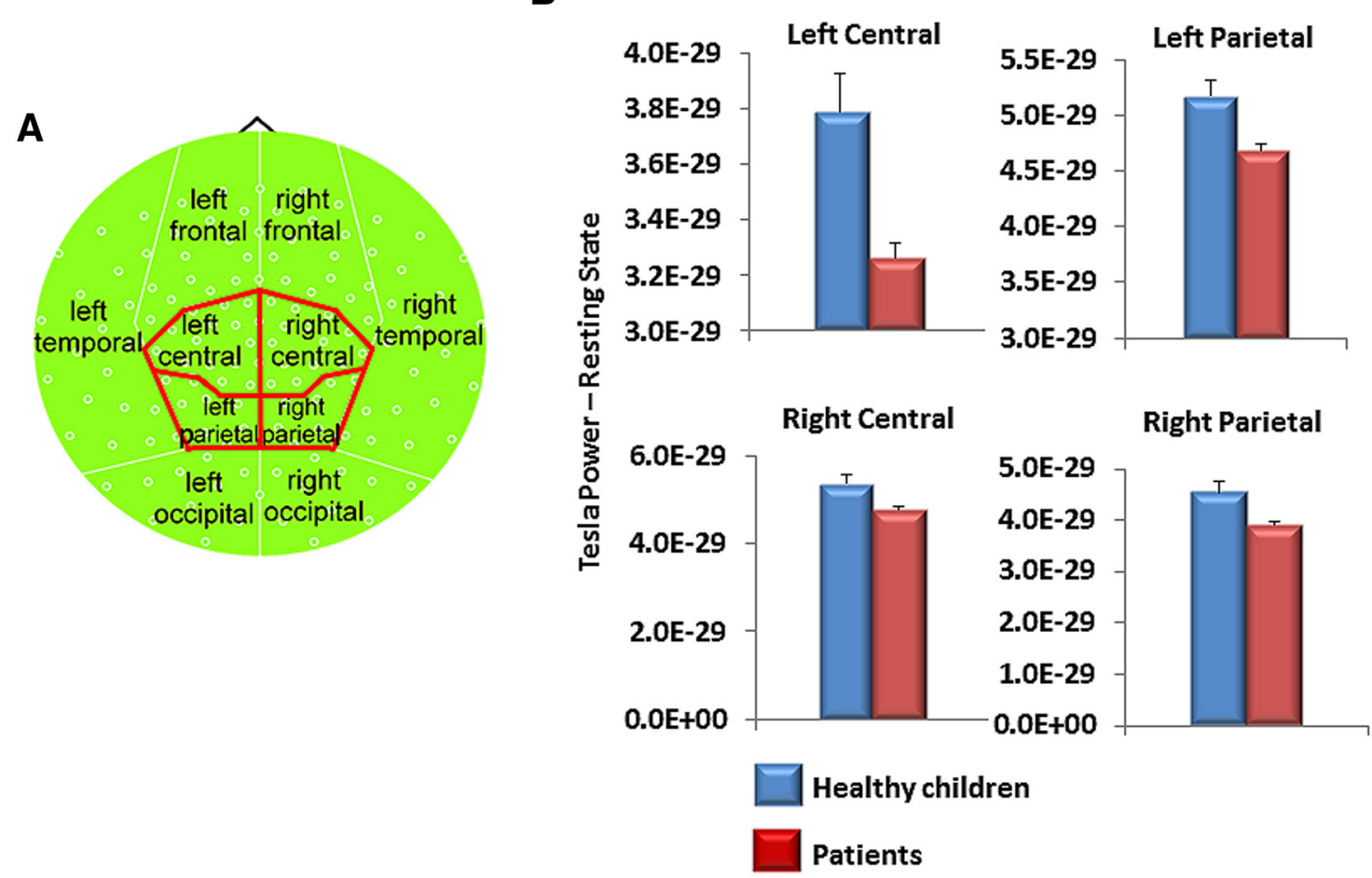

Figure 2. Deficit in regional gamma power in patients during the resting state. $\boldsymbol{A}$, Compartmental organization of regional topoplot analysis is based on the work of Bosma et al. (2008). $\boldsymbol{B}$, Children treated for brain tumors showed lower high-gamma power $(60-100 \mathrm{~Hz})$ in bilateral central and parietal brain regions.

average reaction time $\pm \mathrm{SD}$ fell within this time period for both groups, in both conditions. Only those bandwidths showing whole-brain effects were carried forward in the subsequent analyses.

Regional oscillations. Second, regionally specific estimates in the time course of changes in absolute oscillatory power in bilateral frontal, central, parietal, temporal, and occipital brain regions were examined for each of the 10 topographic compartments. Separate repeated-measures ANOVAs were conducted on the mean power for each region compared with group (patient and healthy children groups) as a between-subjects factor, and task (LLT and HLT) and time (time window) as withinsubjects factors. We then used tests of simple effects (with Bonferroni correction for multiple comparisons) to test for group effects in frequency power in each region, whether or not the overall model was significant. To further reduce the chance of spurious effects, we considered group differences to be significant only if they were evident in clusters that spanned across three or more consecutive epochs.

\section{Baseline period}

We conducted post hoc $t$ tests to determine whether there were baseline group differences in total gamma power only for conditions in which changes in task-related gamma power were significantly different between groups.

Source localization. To localize the neural generators underlying any effects, we applied a scalar beamformer method (i.e., SAM) and we averaged the results by group using the Statistical Parametric Mapping software, as described above.

Correlational analyses. Finally, only those bandwidths and regions where significant effects were identified in our prior analyses were carried forward to test for the relations between frequency power and information-processing speed in patients. Correlation analyses (with Bonferroni corrections for multiple comparisons) were performed between (1) the regional frequency power for time epochs from the LLT and HLT performance, and (2) the PSI from the WISC-IV.

\section{Results}

\section{Reaction time}

All participants were slower on the HLT versus the LLT, indicating that greater effort was required to complete this task. Patients'
Table 1. Reaction time data and analyses

\begin{tabular}{|c|c|c|c|c|c|c|c|}
\hline \multirow[b]{2}{*}{ Data } & \multicolumn{2}{|c|}{ Healthy children } & \multicolumn{2}{|l|}{ Patients } & \multirow[b]{2}{*}{$p$ value } & \multirow[b]{2}{*}{$d f$} & \multirow[b]{2}{*}{ Fstatistic } \\
\hline & Mean RT (ms) & SD & Mean RT (ms) & SD & & & \\
\hline \multicolumn{8}{|l|}{ Task } \\
\hline LLT & 291.61 & 72.98 & 384.37 & 72.99 & 0.000 & & \\
\hline HLT & 429.66 & 93.74 & 503.48 & 93.75 & 0.02 & & \\
\hline Analyses & & & & & 0.000 & & \\
\hline \multicolumn{8}{|l|}{ ANOVA } \\
\hline Group & & & & & 0.002 & 1,36 & 11.00 \\
\hline Task & & & & & 0.000 & 1,36 & 143.8 \\
\hline
\end{tabular}

Findings are from analyses with group (healthy children and patient) as a between-subjects factor and task (LLT and HLT) as a within-subjects factor.

reaction times were slower than those of healthy children across both tasks ( $p$ values $<0.01$; Table 1 ). The error rate for pressing the button on trials with a red cross in the LLT was $\sim 10 \%$ for each group.

\section{Resting-state oscillations}

Across the whole brain, no multivariate difference was evident between the groups in absolute power across bandwidths (Wilks lambda $\left.=0.759, F_{(1,36)}=1.64, p=0.17\right)$. There was a single univariate difference, however, with patients showing greater resting-state theta power compared with control subjects $\left(F_{(1,36)}\right.$ $=5.78, p=0.021)$. Regionally, however, patients had significantly lower total high-gamma power in bilateral central and parietal regions compared with healthy children $(p<0.05$; Fig. 2 ). There were no significant differences between groups in measures of SD.

Task-related changes in whole-brain activity

During the active period ( $\geq 0 \mathrm{~ms}$ from onset of the visual cue), there were main effects of changes in absolute global high-gamma 
Table 2. Significant tests of simple effects for group differences in time epochs for the interaction of group $\times$ task $\times$ time in the whole-brain analyses of high-gamma $(60-100 \mathrm{~Hz})$ power

\begin{tabular}{|c|c|c|c|c|c|}
\hline \multirow[b]{2}{*}{ Time after visual cue (ms) } & \multicolumn{2}{|l|}{ Healthy children } & \multicolumn{2}{|l|}{ Patients } & \multirow[b]{2}{*}{$p$ value } \\
\hline & Mean change in power (tesla) & SD & Mean change in power & SD & \\
\hline \multicolumn{6}{|l|}{ LLT } \\
\hline $1-30$ & $1.54 \mathrm{E}-30$ & $2.58 \mathrm{E}-30$ & $-0.51 \mathrm{E}-30$ & $2.74 \mathrm{E}-30$ & 0.021 \\
\hline $31-60$ & $2.00 \mathrm{E}-30$ & $2.82 \mathrm{E}-30$ & $-0.56 \mathrm{E}-30$ & $3.00 \mathrm{E}-30$ & 0.009 \\
\hline $61-90$ & $5.02 \mathrm{E}-30$ & $5.63 \mathrm{E}-30$ & $-0.6 \mathrm{E}-30$ & $5.99 \mathrm{E}-30$ & 0.004 \\
\hline $91-120$ & $5.39 \mathrm{E}-30$ & $6.01 E-30$ & $-0.65 \mathrm{E}-30$ & $6.41 \mathrm{E}-30$ & 0.004 \\
\hline $121-150$ & $3.56 \mathrm{E}-30$ & $3.66 \mathrm{E}-30$ & $-0.69 \mathrm{E}-30$ & $3.23 \mathrm{E}-30$ & 0.001 \\
\hline \multicolumn{6}{|l|}{ HLT } \\
\hline $31-60$ & $58.69 \mathrm{E}-30$ & 22.27E-30 & $1.15 \mathrm{E}-30$ & $7.89 \mathrm{E}-30$ & 0.000 \\
\hline $61-90$ & $66.5 \mathrm{E}-30$ & $88.49 \mathrm{E}-30$ & $-0.02 \mathrm{E}-30$ & $3.77 \mathrm{E}-30$ & 0.028 \\
\hline $91-120$ & $70.78 \mathrm{E}-30$ & $45.23 \mathrm{E}-30$ & $0.1 \mathrm{E}-30$ & $5.04 \mathrm{E}-30$ & 0.000 \\
\hline $121-150$ & $60.7 \mathrm{E}-30$ & 48.05E-30 & $-0.24 \mathrm{E}-30$ & $14.53 \mathrm{E}-30$ & 0.000 \\
\hline $151-180$ & $31.02 \mathrm{E}-30$ & $36.29 \mathrm{E}-30$ & $-3.29 \mathrm{E}-30$ & $22.65 \mathrm{E}-30$ & 0.007 \\
\hline $181-210$ & $20.42 \mathrm{E}-30$ & $22.47 \mathrm{E}-30$ & $-1.56 \mathrm{E}-30$ & $32.04 \mathrm{E}-30$ & 0.033 \\
\hline $421-450$ & $-5.07 \mathrm{E}-30$ & 17.34E-30 & $3.31 E-30$ & 11.36E-30 & 0.022 \\
\hline
\end{tabular}

power $(60-100 \mathrm{~Hz})$ for group $\left(F_{(1,36)}=7.2, p=0.011\right)$, task $\left(F_{(1,36)}=10.79, p=0.002\right)$, and time $\left(F_{(19,18)}=5.98, p=0.000\right)$, and for task $\times$ group interactions $\left(F_{(1,36)}=7.48, p=0.01\right)$, time $\times$ group interactions $\left(F_{(19,18)}=9.35, p=0.000\right)$, and task $\times$ time interactions $\left(F_{(19,18)}=5.23, p=0.000\right)$. All main effects and lower-order interactions were interpreted in the context of a three-way interaction among task $\times$ time $\times$ group $\left(F_{(1,36)}=5.71\right.$, $p=0.000)$. Tests of simple effects for this interaction showed that the healthy children had a greater increase in absolute highgamma power during task performance than children treated for brain tumors, that the increase was greater in the higher load task, and that the increase occurred in the early time epochs for both tasks (Table 2). Patients showed little change in absolute highgamma power and no association with load (Fig. 3). There were no significant differences between groups in measures of SD. Analyses were also conducted for delta $(0.5-3 \mathrm{~Hz})$, theta $(4-7$ $\mathrm{Hz})$, alpha $(8-12 \mathrm{~Hz})$, beta $(13-29 \mathrm{~Hz})$, and low gamma (30-59 $\mathrm{Hz}$ ) bandwidths; however, there were no significant effects for any of these bandwidths.

Task-related whole-brain baseline measures

In the baseline period ( -30 to $0 \mathrm{~ms}$ of visual cue onset), healthy children showed significantly more total whole-brain highgamma power than patients for both the LLT $\left(t_{(58)}=4.73, p<\right.$ $0.0001)$ and $\operatorname{HLT}\left(t_{(58)}=3.65, p=0.0006\right)$ paradigms. To visually depict changes in absolute high-gamma power within each group, we plotted the changes in total high-gamma power and measured the peak change in power from baseline for each group separately. Although patients had significantly lower total highgamma power, they showed a greater relative potentiation of high-gamma across the whole brain in the LLT, but not the HLT (Fig. 4).

\section{Task-related changes in regional activity}

For the left central region, there was a main effect of time $\left(F_{(9,28)}\right.$ $=5.3, p=0.000)$ and time $\times$ group interactions $\left(F_{(9,28)}=4.26\right.$, $p=0.002)$ and time interactions task interactions $\left(F_{(9,28)}=2.6\right.$, $p=0.025)$, which were interpreted in the context of a three-way task $\times$ time $\times$ group interaction $\left(F_{(9,28)}=3.13, p=0.01\right)$. Tests of simple effects showed that the healthy children exhibited a greater increase in left central absolute high-gamma power during task performance than children treated for brain tumors, and that this difference was greater in the HLT, and in the early and middle stages of the trial (180-390 ms; Table 3, Fig. 5). Healthy children also displayed more absolute high-gamma power (60$100 \mathrm{~Hz}$ ) than patients in the right occipital, left parietal, right parietal, and left frontal topographic regions for the HLT only (Table 4). There were no significant differences among groups in measures of SD.

\section{Task-related regional baseline measures}

In the baseline period ( -30 to $0 \mathrm{~ms}$ of visual cue onset), healthy children showed significantly more total left central high-gamma power than patients for both the $\operatorname{LLT}\left(t_{(58)}=3.015, p=0.0038\right)$ and $\operatorname{HLT}\left(t_{(58)}=5.69, p<0.0001\right)$ paradigms. To visually depict changes in the left central region in absolute high-gamma power within each group, we plotted the changes in total high-gamma power and measured the peak change in power from baseline for each group separately: although patients had significantly lower total high-gamma power, they showed a greater relative potentiation of high-gamma power in the left central region in the LLT, but not in the HLT (Fig. 6). Note that evidence of relative changes in gamma power from baseline in this lower cognitive load paradigm was published in our earlier study for the majority of our participants [previous parameters: $30-100 \mathrm{~Hz}$; single time window across entire trial; and contralateral motor cortex (MIc) virtual sensor coordinate]. This earlier finding is similar to our topographic results of $60-100 \mathrm{~Hz}$ for this region.

\section{Neural generators of the high-gamma response}

Based on source localization, left central gamma power (60-100 $\mathrm{Hz}$ ) during both tasks was localized to the motor cortex (BA4), with healthy children showing markedly greater power than patients (Fig. $7 A, B$ ). As all participants were right handed, this region corresponded to their MIc. Right occipital source power was localized to the right primary visual cortex (BA18), and parietal source power to the bilateral regions of the primary somatosensory cortices (BA3). Other prominent HLT source powers were localized in the anterior cingulate cortex (ACC; BA24) and the posterior cingulate cortex (PCC; BA23, A29, and A30), respectively (Fig. 5C-F). Overall, patients displayed lower high-gamma power in these regions.

\section{Correlations between gamma power and cognitive performance}

Finally, we examined whether high-gamma power predicted cognitive performance. There were no significant relations between MEG reaction times and total high-gamma power during resting 
A

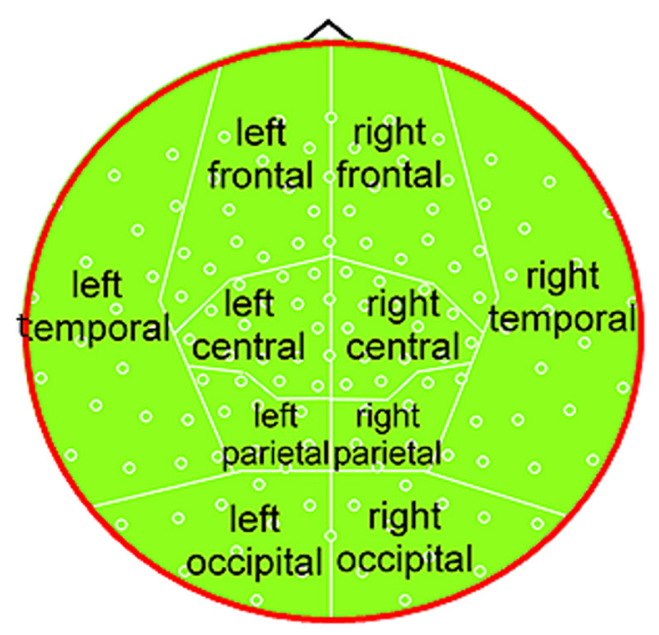

B
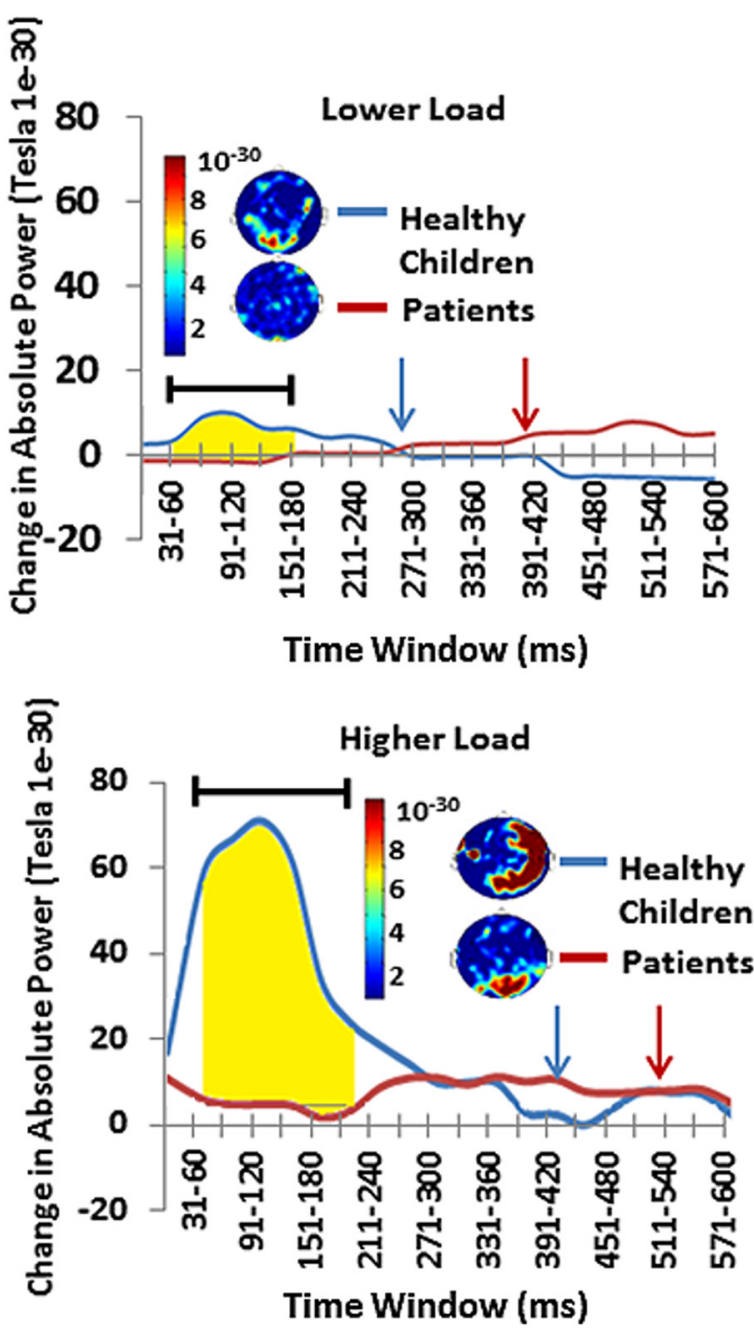

Figure 3. Across the whole brain healthy children showed significantly greater high-gamma power $(60-100 \mathrm{~Hz})$ in the LLT and HLT than patients. $\boldsymbol{A}$, Topoplot map of high-gamma power used for these analyses. $\boldsymbol{B}$, Time representation of whole-brain high-gamma activity across trials. The blue arrow depicts mean reaction time for healthy control subjects; the red arrow depicts the mean reaction time for patients. Highlighted regions represent epochs in which there were significant group differences in gamma power. See also Table 2.

state in either group. However, patients showed a significant correlation between less of an increase in high-gamma power (left central region) and slower reaction times at several time windows during LLT performance (151-180 ms: $r=-0.71, p=0.0005$; $181-210 \mathrm{~ms}: r=-0.71, p=0.0005 ; 211-240 \mathrm{~ms}: r=-0.71, p=$ 0.0005 ; 301-330 ms: $r=-0.69, p=0.0008$; 361-390 ms: $r=$ $-0.68, p=0.001$; 391-420 ms: $r=-0.68, p=0.001 ; 421-450$ ms: $r=-0.68, p=0.001)$. In healthy children, greater increases in whole-brain high-gamma power $(60-100 \mathrm{~Hz})$ immediately after the visual cue predicted faster reaction times in the HLT (31-60 ms: $r=-0.7, p=0.0012$ ). There was no relationship between high-gamma power increases and reaction time in patients on the HLT; however, smaller increases in high-gamma power on the HLT predicted slower processing speeds on the WISC-IV (181-210 ms: $r=0.67, p=0.0012 ; 211-239$ ms: $r=$ $0.62, p=0.0035 ; 240-270 \mathrm{~ms}: r=0.70, p=0.0006)$, suggesting that gamma characteristics in the MEG task could predict broader cognitive impairment outside the MEG in patients.

\section{Discussion}

We present novel evidence that high-gamma oscillations (60$100 \mathrm{~Hz}$ ) are disrupted in children treated with CRT for brain tumors of the posterior fossa. Overall, these children had lower total high-gamma power and lower total increases in highgamma power during task performance, regardless of cognitive load. Reduced levels of total high-gamma power were correlated with poorer task performance in these children. In contrast, healthy children demonstrated higher total high-gamma power, and significant total increases in response to task requirements and increased cognitive load. Moreover, these increases in highgamma power were correlated with faster response times during task performance in healthy children. Lower levels of total highgamma power $(60-100 \mathrm{~Hz})$ at rest and during task performance may be an index of impaired information processing in the developing brain. As a lack of gamma power was observed consistently across resting, task-baseline, and task-active states, and varying stages of cognitive demand, we also suggest that characteristics of neural oscillations that persist between resting state and task operations may be an ideal biomarker for populations whose deficits become apparent during cognitive performance.

The relationship of increases in total high-gamma power to task performance and increased cognitive load may reflect increased synchrony of fast oscillations recruited to support functions underlying task performance, such as perceptual processing [60-250 Hz (Edwards et al., 2005); 40-200 Hz (Lachaux et al., 


\section{A Lower Load - Baseline}

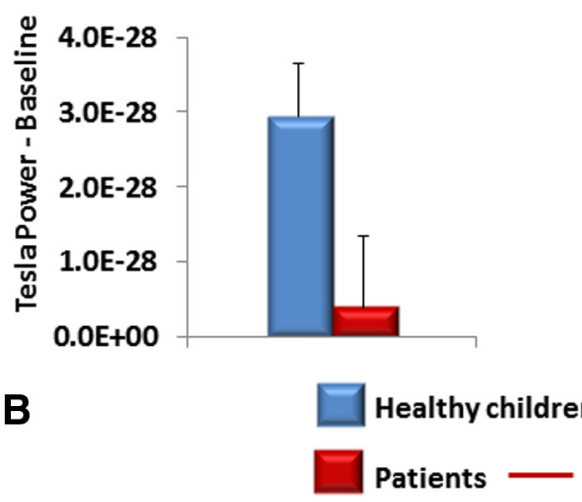

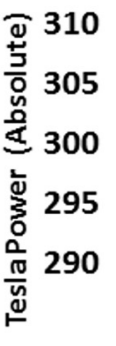

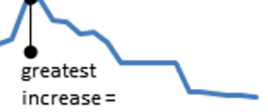

$2.87 \%$

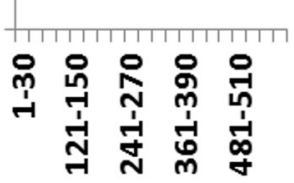

Time Window (ms)
Lower Load - Task Performance

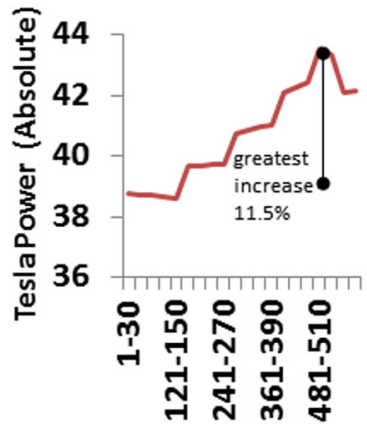

Time Window (ms)
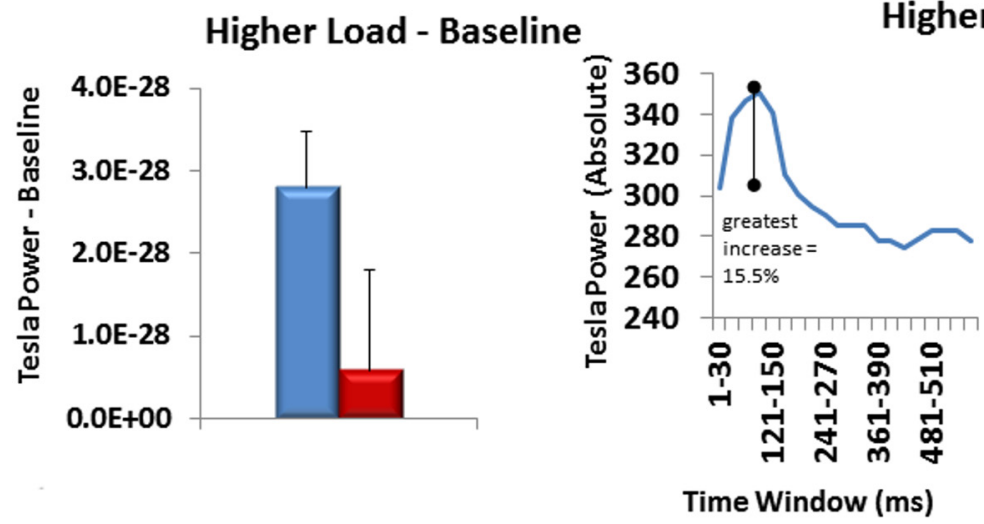

Higher Load - Task Performance

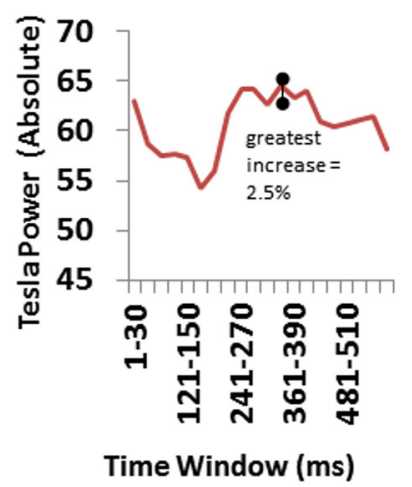

Figure 4. $\quad \boldsymbol{A}, \boldsymbol{B}$, Baseline period whole-brain high-gamma levels and separate group total gamma responses for LLT (A) and HLT (B).

\begin{tabular}{|c|c|c|c|c|c|}
\hline \multirow[b]{2}{*}{$\begin{array}{l}\text { Time after visual } \\
\text { cue (ms) }\end{array}$} & \multicolumn{2}{|l|}{ Healthy children } & \multicolumn{2}{|l|}{ Patients } & \multirow[b]{2}{*}{$p$ value } \\
\hline & $\begin{array}{l}\text { Mean change in } \\
\text { power (tesla) }\end{array}$ & SD & $\begin{array}{l}\text { Mean change in } \\
\text { power }\end{array}$ & SD & \\
\hline \multicolumn{6}{|l|}{ LLT } \\
\hline $181-210$ & $33.2 \mathrm{E}-30$ & $3.46 \mathrm{E}-30$ & $0.39 \mathrm{E}-30$ & $36.86 \mathrm{E}-30$ & 0.006 \\
\hline $211-240$ & $63.3 \mathrm{E}-30$ & $85.8 \mathrm{E}-30$ & $3.68 \mathrm{E}-30$ & $91.47 \mathrm{E}-30$ & 0.041 \\
\hline $241-270$ & $40.77 \mathrm{E}-30$ & $46.62 \mathrm{E}-30$ & $6.83 \mathrm{E}-30$ & 4.44E-30 & 0.018 \\
\hline $271-300$ & $61.61 \mathrm{E}-30$ & $62.32 \mathrm{E}-30$ & 22.21E-30 & $5.94 \mathrm{E}-30$ & 0.038 \\
\hline $301-330$ & $50.72 \mathrm{E}-30$ & $44.6 \mathrm{E}-30$ & $13.49 \mathrm{E}-30$ & $47.53 \mathrm{E}-30$ & 0.015 \\
\hline $331-360$ & 56.11E-30 & 46.61E-30 & 18.47E-30 & 49.18E-30 & 0.018 \\
\hline \multicolumn{6}{|l|}{ HLT } \\
\hline $361-390$ & 78.77E-30 & $49.18 \mathrm{E}-30$ & 14.54E-30 & 52.44E-30 & 0.000 \\
\hline $391-420$ & $163.6 \mathrm{E}-30$ & 131.77E-30 & 15.27E-30 & $140.51 E-30$ & 0.002 \\
\hline $421-450$ & 201.43E-30 & 190.39E-30 & 18.47E-30 & 203.29E-30 & 0.005 \\
\hline $451-480$ & 206.01E-30 & 209.2E-30 & $33.21 E-30$ & $223.02 \mathrm{E}-30$ & 0.016 \\
\hline $481-510$ & $182.25 \mathrm{E}-30$ & 186.44E-30 & 29.74E-30 & 198.71E-30 & 0.017 \\
\hline
\end{tabular}

2007)], attention [ $\geq 60 \mathrm{~Hz}$ (Hauck et al., 2007; Ray et al., 2008)], and volitional movement [65-80 Hz (Cheyne et al., 2008); 62-87 $\mathrm{Hz}$ (Waldert et al., 2008); 75-100 Hz (Crone et al., 1998)]. The observation that further gamma potentiation did not occur in patients during the higher load task, relative to the lower load task, suggests that high-gamma power had reached an asymptote and further potentiation in response to a more difficult task was not possible. We recently published findings that children treated for brain tumors with CRT qualitatively showed relatively greater increases from baseline in visual and motor gamma power (30$100 \mathrm{~Hz}$ ) during a lower load visual-motor reaction time task
(Dockstader et al., 2013). The current findings add important insight into these earlier findings. We propose that children treated with CRT have reduced total high-gamma power $(60-$ $100 \mathrm{~Hz}$ ) and that global or regional relative increases compared with healthy control children during task performance may reflect compensatory mechanisms for total gamma loss in the lower load task (Fig. 8). Compensatory increases in gamma activity during task performance have been documented in other clinical populations with suggested gamma deficits (Buard et al., 2013; Florin et al., 2013). As gamma synchrony is thought to reflect neural computations underlying numerous higher-order processes (Fries, 2009), reduced synchrony power of these fastest oscillations suggests that computational processes may be compromised in patients, which leads to impaired task performance. The lack of total high-gamma power in our patients may reflect the limited capacity of their brains to fire in synchrony at the fastest oscillations.

Gamma deficits in patients were specific to the high-gamma band $(60-100 \mathrm{~Hz})$. While gamma oscillations are often portrayed with a broadly defined frequency range of $30-100 \mathrm{~Hz}$, we did not show any group differences in gamma-band modulations from 30 to $59 \mathrm{~Hz}$. The fact that high-gamma deficits correlated with poor processing speeds in our patients suggests that oscillations of $>60 \mathrm{~Hz}$ play a critical role in our task. Other studies have demonstrated that event-related activations of $>60 \mathrm{~Hz}$ are reliably associated with processing speeds (Brücke et al., 2013), attentional modulation (Hauck et al., 2007; Ray et al., 2008), and decision making (Guggisberg et al., 2007). Moreover, very circumscribed deficits in high-gamma power have been reported in other clinical populations with cognitive impairments (Sun et al., 

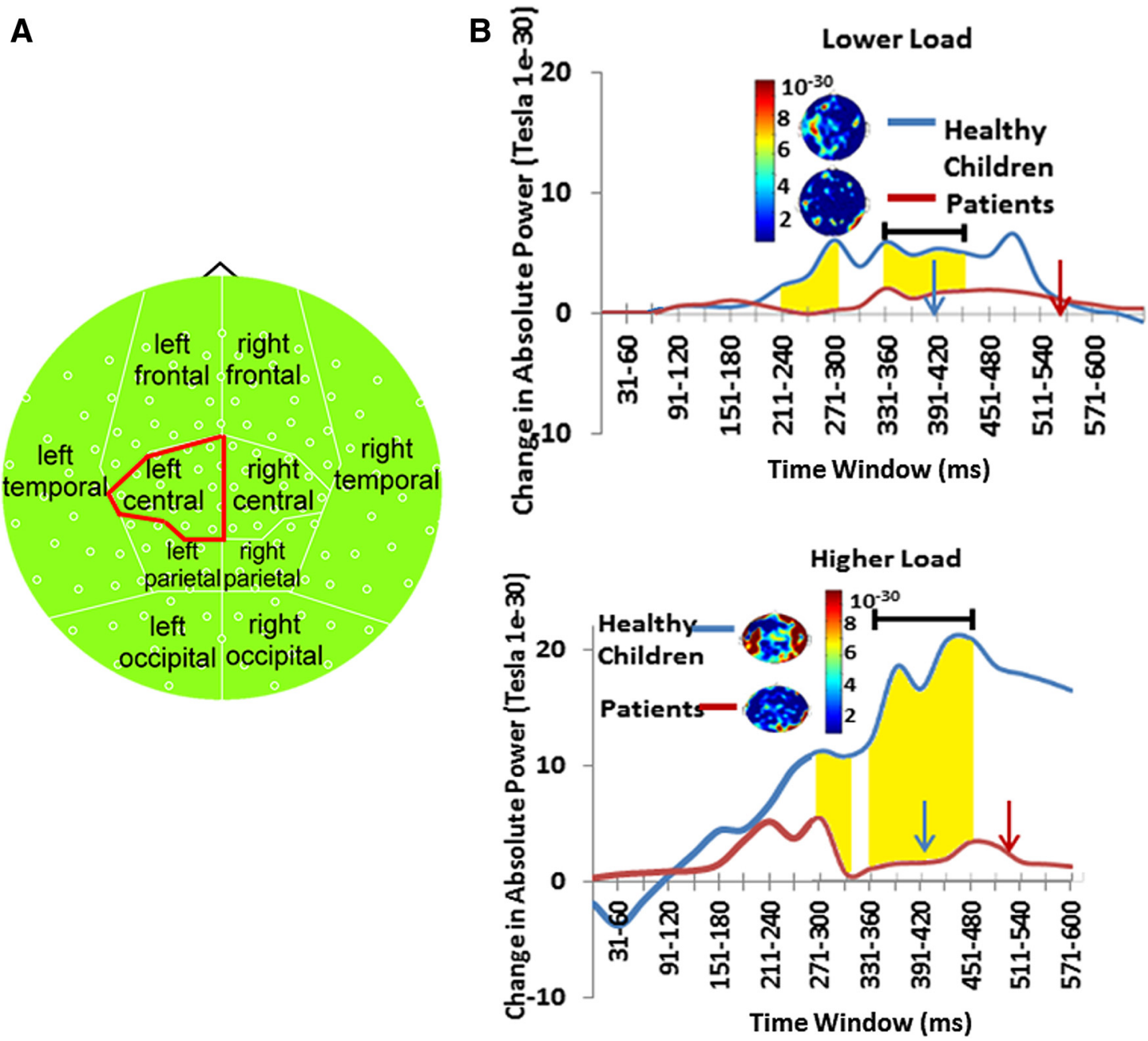

Figure 5. Healthy children showed significantly more fast-wave gamma power $(60-100 \mathrm{~Hz})$ reactivity in the left central region from the LLT to the HLT than patients. A, Topoplot map of high-gamma power used for these analyses. $\boldsymbol{B}$, Time representation of whole-brain high-gamma power activity across trials. The blue arrow depicts the mean reaction time for healthy control subjects; the red arrow depicts the mean reaction time for patients. Highlighted regions represent epochs in which there were significant group differences in gamma power. See also Table 3.

2012, 2013; Snijders et al., 2013). Future work might reveal that specific cognitive effects are best characterized within well defined gamma sub-bands.

Both global and regional total high-gamma power differences were shown between our groups. Global increases in oscillatory power can reflect increases in long-range connectivity when multiple cortical regions are involved in task performance and localized increases in communication in task-specific cortical regions (Fries et al., 2001; Fries, 2005). Since cognitive functions are thought to depend on integrated activity across specialized brain regions, either global changes or regional changes in oscillatory activities may influence the performance of cognitive tasks in a population where tumor location is specific but treatment effects (such as chemotherapy and whole-brain CRT) are diffuse across the entire brain. In our study, the relationship of increases in gamma power to increases in processing speed was particularly associated with the MIc on our visual-motor tasks. Gamma power increases in MIc that occurred just before, and during, the motor response may reflect the activity of cortico-subcortical networks involved in feedback control for motor performance (Cheyne et al., 2008). With increased cognitive load, increases in gamma power were potentiated in the healthy children, which may also enhance regional communication relevant for efficient task performance when cognitive demand is increased (Fries et al., 2001; Fries, 2005).

The more demanding task also elicited increased gamma responses from several other neural generators, including the bilateral somatosensory cortices and the dorsal ACC and PCC. The dorsal part of the ACC is connected with the prefrontal cortex and parietal cortex, as well as the motor system and the frontal eye fields, making it a central station for processing top-down and bottom-up stimuli and assigning appropriate control to other areas in the brain. The ACC seems to be especially involved when effort is needed to carry out a task (Botvinick et al., 1999; Bush et al., 1999; Carter et al., 1999). Although there is less certainty about the function of the posterior cingulate cortex, PCC subregions showed distinct patterns of activity modulation during the performance of an attentionally demanding task (Leech and Sharp, 2014). Although our patients showed peaks in each of these regions, they showed lower total gamma power in these regions than the healthy control children. These observations suggest an overall lack of gamma rhythmicity in many neural regions in children treated for brain tumors with cranial radiation. They also suggest that task performance in this population may be compromised by task-specific regional requirements of increased gamma power during activities. The fact that the beam- 
Table 4. Planned tests of simple effects for group differences in time epochs for high-gamma $(60-100 \mathrm{~Hz})$ power across all remaining brain regions

\begin{tabular}{|c|c|c|c|c|c|}
\hline \multirow[b]{2}{*}{ Time after visual cue (ms) } & \multicolumn{2}{|l|}{ Healthy children } & \multicolumn{2}{|l|}{ Patients } & \multirow[b]{2}{*}{$p$ value } \\
\hline & Mean change in power (tesla) & SD & Mean change in power & SD & \\
\hline \multicolumn{6}{|l|}{ Left frontal } \\
\hline $421-450$ & 20603.9E-30 & $21682 E-30$ & 2895.33E-30 & $23116 \mathrm{E}-30$ & 0.018 \\
\hline $451-480$ & 20772E-30 & $22393 \mathrm{E}-30$ & 1827.14E-30 & $23878 E-30$ & 0.014 \\
\hline $481-510$ & $25770 \mathrm{E}-30$ & $29913 \mathrm{E}-30$ & $824.00 \mathrm{E}-30$ & $31891 \mathrm{E}-30$ & 0.015 \\
\hline \multicolumn{6}{|l|}{ Left parietal } \\
\hline $391-420$ & $235.13 \mathrm{E}-30$ & $318.28 \mathrm{E}-30$ & $-64.3 \mathrm{E}-30$ & $301.94 \mathrm{E}-30$ & 0.007 \\
\hline $421-450$ & $938.98 \mathrm{E}-30$ & $1257 \mathrm{E}-30$ & $-57.94 \mathrm{E}-30$ & $1193 \mathrm{E}-30$ & 0.021 \\
\hline $451-480$ & 1000.16E-30 & $1308 \mathrm{E}-30$ & $-49.24 \mathrm{E}-30$ & 1237E-30 & 0.020 \\
\hline $481-510$ & 1153.13E-30 & 1517E-30 & $-70.05 E-30$ & $1439.3 \mathrm{E}-30$ & 0.019 \\
\hline $511-540$ & $970.26 \mathrm{E}-30$ & $1221 E-30$ & $32.26 \mathrm{E}-30$ & $1158 \mathrm{E}-30$ & 0.025 \\
\hline $541-570$ & 797.39E-30 & $963.31 E-30$ & 11.11E-30 & $913.88 \mathrm{E}-30$ & 0.039 \\
\hline \multicolumn{6}{|l|}{ Right parietal } \\
\hline $301-330$ & $76.31 E-30$ & 87.49E-30 & $-7.0 \mathrm{E}-30$ & $82.99 \mathrm{E}-30$ & 0.006 \\
\hline $331-360$ & $146.22 \mathrm{E}-30$ & 161.E-30 & $-8.9 \mathrm{E}-30$ & 153.09E-30 & 0.006 \\
\hline $361-390$ & 166.56E-30 & $181 E-30$ & $-10.85 \mathrm{E}-30$ & 171.91E-30 & 0.005 \\
\hline $391-420$ & 186.9E-30 & 201E-30 & $-3.78 \mathrm{E}-30$ & $190.68 \mathrm{E}-30$ & 0.006 \\
\hline $421-450$ & 144.35E-30 & $140 \mathrm{E}-30$ & $-1.08 \mathrm{E}-30$ & 133.01E-30 & 0.003 \\
\hline $480-510$ & 118.15E-30 & $125 \mathrm{E}-30$ & $1.95 \mathrm{E}-30$ & $118.86 \mathrm{E}-30$ & 0.008 \\
\hline $511-540$ & 111.29E-30 & $119 \mathrm{E}-30$ & $-12.67 \mathrm{E}-30$ & $113.02 E-30$ & 0.003 \\
\hline $541-570$ & 104.44E-30 & $1227 \mathrm{E}-30$ & $-24.48 \mathrm{E}-30$ & $116.42 \mathrm{E}-30$ & 0.002 \\
\hline \multicolumn{6}{|l|}{ Right occipital } \\
\hline $391-420$ & $340.89 \mathrm{E}-30$ & $504.0 \mathrm{E}-30$ & $-80.48 \mathrm{E}-30$ & $478 \mathrm{E}-30$ & 0.015 \\
\hline $421-450$ & $576.69 \mathrm{E}-30$ & $839 \mathrm{E}-30$ & $-69.99 \mathrm{E}-30$ & 79.7E-30 & 0.025 \\
\hline $451-480$ & $605.13 \mathrm{E}-30$ & $851 E-30$ & $-42.87 \mathrm{E}-30$ & $808.25 \mathrm{E}-30$ & 0.026 \\
\hline $481-510$ & $766.04 \mathrm{E}-30$ & 1067E-30 & $-53.31 \mathrm{E}-30$ & 1012E-30 & 0.025 \\
\hline
\end{tabular}

A

A Lower Load - Baseline

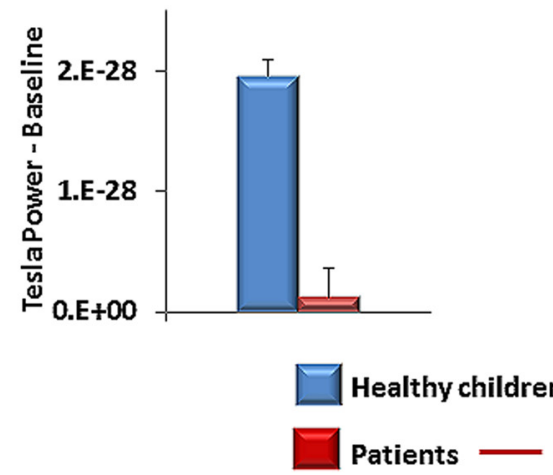

B

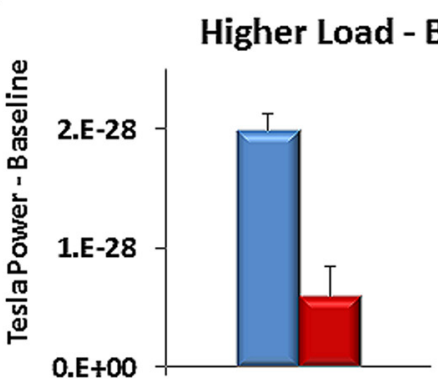

Lower Load - Task Performance

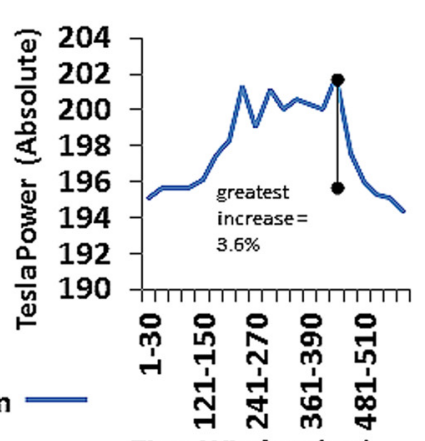

Time Window (ms)

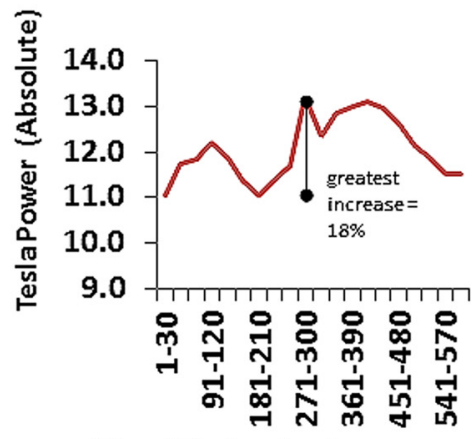

Time Window (ms) 

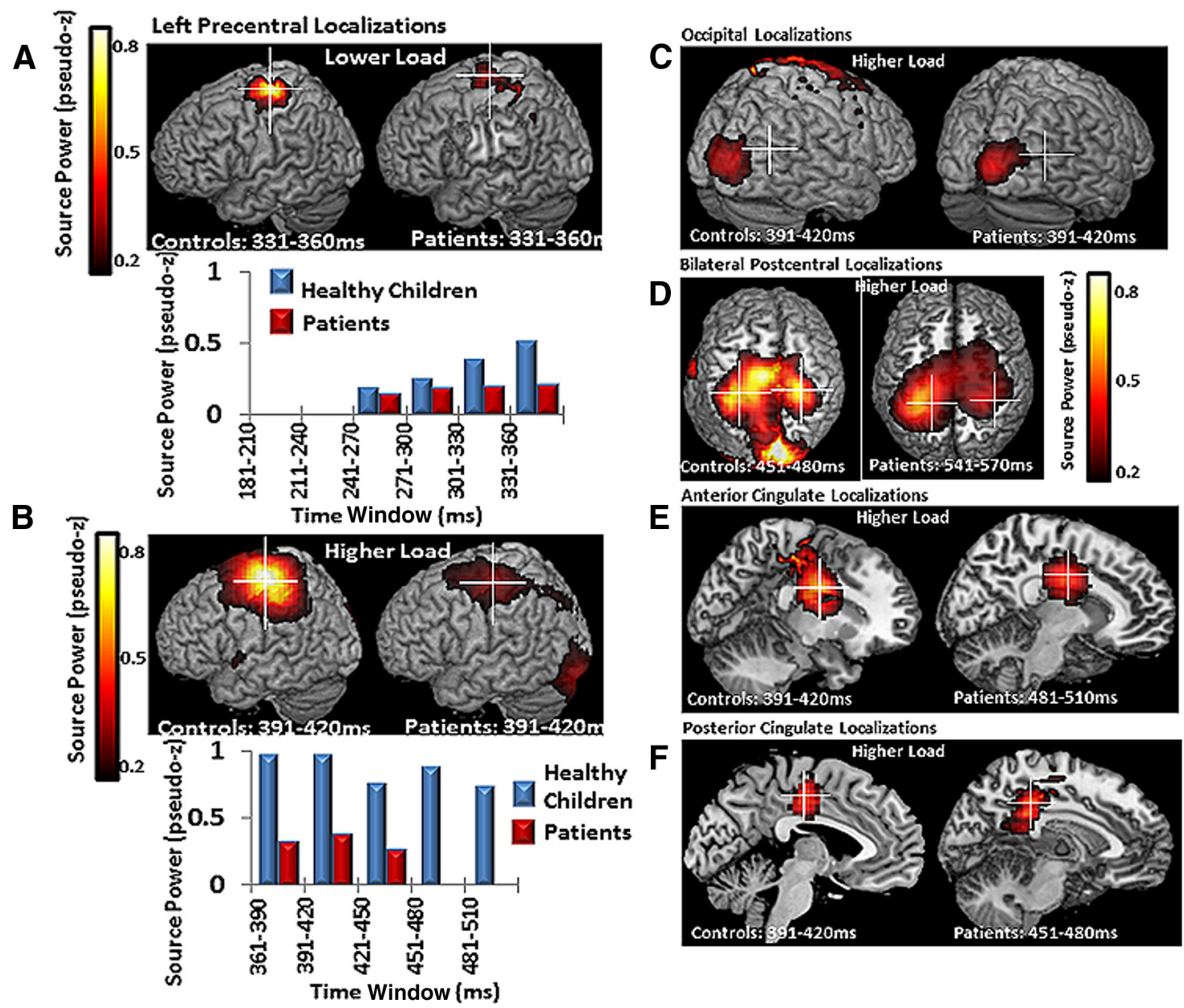

Figure 7. Left central region gamma reactivity was localized to the left precentral gyrus, BA 4, and MIc. A, Healthy children showed markedly more MIc high-gamma power than patients in both tasks. The corresponding time course and power values are shown in $\boldsymbol{B} . \boldsymbol{C}-\boldsymbol{F}$, Regional group differences in high-gamma power localized to the right primary visual cortex, BA 18 (C); bilateral somatosensory cortices, BA3 (D); right ACC, BA $24(\boldsymbol{E})$; and left PCC, BA 23, 29, and $30(\boldsymbol{F})$. Time windows shown were the windows in which group-averaged activity was most robust. See also Table 4.

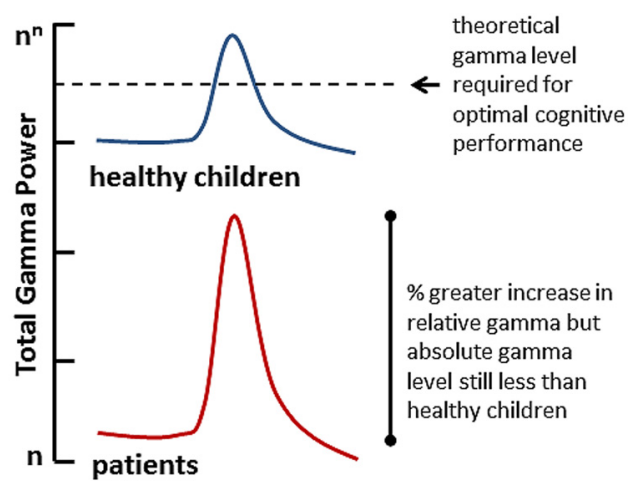

Neural Response To Cognitive Demand

Figure 8. Hypothesized high-gamma power $(60-100 \mathrm{~Hz})$ neural response to cognitive demand in healthy children and children treated for brain tumors with CRT. We propose that children treated with CRT have reduced total high-gamma power $(60-100 \mathrm{~Hz})$ and that relative high-gamma increases compared with healthy control children in the lower load task may reflect compensatory mechanisms for lower levels of absolute gamma power. The observation that further gamma potentiation did not occur in patients during the higher load task, relative to the lower load task, suggests that high-gamma power has an asymptote in this population, which makes further potentiation in response to a more difficult task impossible. The lack of total high-gamma power in our patients may reflect the limited capacity of their brains to fire in synchrony at the fastest oscillations.
The current findings suggest that patients show a reduced fast-oscillation response after treatment for brain tumors. Although factors such as tumor pathology, radiation dose, and amount of resection may all contribute differentially to high oscillation synchrony, we did not have a large enough sample to consider these variables and our patient population. Moreover, our patient sample is heterogeneous in terms of tumor type and radiation dose. However, when tumor variables are controlled for, $\mathrm{CRT}$ is more associated with declines in processing speed, IQ, and working memory performance than surgery-only or surgery and chemotherapy treatment in pediatric posterior fossa tumor populations (Anderson et al., 1997; Schatz et al., 2000b; Langer et al., 2002). Brain-based explanations for CRT-related behavioral delays in information-processing speed include radiationinduced mechanical disruptions in relaying neural signals such as injury to existing white matter that modulates conduction times and synchrony of impulse conduction (Fields, 2008a,b) or damage to glial progenitor cells that regulate future myelination and neurotransmitter functions that are important for neural transmission (Monje et al., 2002; Dietrich and Kempermann, 2006; Roy et al., 2007). Future directions for study should include investigating whether compromised white matter structure is related to abnormal neuronal activation after CRT and whether treatment with surgery alone, or surgery and chemo- 
therapy without CRT, and other patient variables predict gamma deficits.

In summary, we present novel and compelling evidence that the power of high-gamma oscillations $(60-100 \mathrm{~Hz})$ may directly index how quickly the brain can process information. Understanding how neural injury transgresses into cognitive impairment is critical to the development of appropriate intervention and rehabilitation strategies. We submit that the amount of total high-gamma power is a robust reflection of normal and impaired information processing.

\section{References}

Anderson CA, Arciniegas DB (2010) Cognitive sequelae of hypoxicischemic brain injury: a review. NeuroRehabilitation 26:47-63. CrossRef Medline

Anderson V, Godber T, Smibert E, Ekert H (1997) Neurobehavioural sequelae following cranial irradiation and chemotherapy in children: an analysis of risk factors. Pediatr Rehabil 1:63-76. Medline

Askins MA, Moore BD 3rd (2008) Preventing neurocognitive late effects in childhood cancer survivors. J Child Neurol 23:1160-1171. CrossRef Medline

Berger A, Sadeh M, Tzur G, Shuper A, Kornreich L, Inbar D, Cohen IJ, Michowiz S, Yaniv I, Constantini S, Kessler Y, Meiran N (2005) Task switching after cerebellar damage. Neuropsychology 19:362-370. CrossRef Medline

Bosma I, Stam CJ, Douw L, Bartolomei F, Heimans JJ, van Dijk BW, Postma TJ, Klein M, Reijneveld JC (2008) The influence of low-grade glioma on resting state oscillatory brain activity: a magnetoencephalography study. J Neurooncol 88:77-85. CrossRef Medline

Botvinick M, Nystrom LE, Fissell K, Carter CS, Cohen JD (1999) Conflict monitoring versus selection-for-action in anterior cingulate cortex. Nature 402:179-181. CrossRef Medline

Brovelli A, Lachaux JP, Kahane P, Boussaoud D (2005) High gamma frequency oscillatory activity dissociates attention from intention in the human premotor cortex. Neuroimage 28:154-164. CrossRef Medline

Broyd SJ, Demanuele C, Debener S, Helps SK, James CJ, Sonuga-Barke EJ (2009) Default-mode brain dysfunction in mental disorders: a systematic review. Neurosci Biobehav Rev 33:279-296. CrossRef Medline

Brücke C, Bock A, Huebl J, Krauss JK, Schönecker T, Schneider GH, Brown P, Kühn AA (2013) Thalamic gamma oscillations correlate with reaction time in a Go/noGo task in patients with essential tremor. Neuroimage 75:36-45. CrossRef Medline

Buard I, Rogers SJ, Hepburn S, Kronberg E, Rojas DC (2013) Altered oscillation patterns and connectivity during picture naming in autism. Front Hum Neurosci 7:742. CrossRef Medline

Bush G, Frazier JA, Rauch SL, Seidman LJ, Whalen PJ, Jenike MA, Rosen BR, Biederman J (1999) Anterior cingulate cortex dysfunction in attentiondeficit/hyperactivity disorder revealed by fMRI and the Counting Stroop. Biol Psychiatry 45:1542-1552. CrossRef Medline

Carter CS, Botvinick MM, Cohen JD (1999) The contribution of the anterior cingulate cortex to executive processes in cognition. Rev Neurosci 10:49-57. Medline

Cheyne D, Bells S, Ferrari P, Gaetz W, Bostan AC (2008) Self-paced movements induce high-frequency gamma oscillations in primary motor cortex. Neuroimage 42:332-342. CrossRef Medline

Cheyne D, Jobst C, Tesan G, Crain S, Johnson B (2014) Movement-related neuromagnetic fields in preschool age children. Hum Brain Mapp. Advance online publication. Retrieved May 28, 2014. doi:10.1002/ hbm.22518. CrossRef Medline

Colonnese M, Khazipov R (2012) Spontaneous activity in developing sensory circuits: implications for resting state fMRI. Neuroimage 62:22122221. CrossRef Medline

Crone NE, Miglioretti DL, Gordon B, Lesser RP (1998) Functional mapping of human sensorimotor cortex with electrocorticographic spectral analysis. II. Event-related synchronization in the gamma band. Brain 121: 2301-2315. CrossRef Medline

Dietrich J, Kempermann G (2006) Role of endogenous neural stem cells in neurological disease and brain repair. Adv Exp Med Biol 557:191-220. CrossRef Medline

Dockree PM, Robertson IH (2011) Electrophysiological markers of cogni- tive deficits in traumatic brain injury: a review. Int J Psychophysiol 82:5360. CrossRef Medline

Dockstader C, Gaetz W, Bouffet E, Tabori U, Wang F, Bostan SR, Laughlin S, Mabbott DJ (2013) Neural correlates of delayed visual-motor performance in children treated for brain tumours. Cortex 49:2140-2150. CrossRef Medline

Edwards E, Soltani M, Deouell LY, Berger MS, Knight RT (2005) High gamma activity in response to deviant auditory stimuli recorded directly from human cortex. J Neurophysiol 94:4269-4280. CrossRef Medline

Fields RD (2008a) White matter in learning, cognition and psychiatric disorders. Trends Neurosci 31:361-370. CrossRef Medline

Fields RD (2008b) Oligodendrocytes changing the rules: action potentials in glia and oligodendrocytes controlling action potentials. Neuroscientist 14:540-543. CrossRef Medline

Florin E, Erasmi R, Reck C, Maarouf M, Schnitzler A, Fink GR, Timmermann L (2013) Does increased gamma activity in patients suffering from Parkinson's disease counteract the movement inhibiting beta activity? Neuroscience 237:42-50. CrossRef Medline

Fries P (2005) A mechanism for cognitive dynamics: neuronal communication through neuronal coherence. Trends Cogn Sci 9:474-480. CrossRef Medline

Fries P (2009) Neuronal gamma-band synchronization as a fundamental process in cortical computation. Annu Rev Neurosci 32:209-224. CrossRef Medline

Fries P, Reynolds JH, Rorie AE, Desimone R (2001) Modulation of oscillatory neuronal synchronization by selective visual attention. Science 291: 1560-1563. CrossRef Medline

Gaetz W, Liu C, Zhu H, Bloy L, Roberts TP (2013) Evidence for a motor gamma-band network governing response interference. Neuroimage 74 : 245-253. CrossRef Medline

Greicius M (2008) Resting-state functional connectivity in neuropsychiatric disorders. Curr Opin Neurol 21:424-430. CrossRef Medline

Grent-'t-Jong T, Oostenveld R, Jensen O, Medendorp WP, Praamstra P (2013) Oscillatory dynamics of response competition in human sensorimotor cortex. Neuroimage 83:27-34. CrossRef Medline

Guggisberg AG, Dalal SS, Findlay AM, Nagarajan SS (2007) High-frequency oscillations in distributed neural networks reveal the dynamics of human decision making. Front Hum Neurosci 1:14. CrossRef Medline

Haig AR, Gordon E, De Pascalis V, Meares RA, Bahramali H, Harris A (2000) Gamma activity in schizophrenia: evidence of impaired network binding? Clin Neurophysiol 111:1461-1468. CrossRef Medline

Hauck M, Lorenz J, Engel AK (2007) Attention to painful stimulation enhances gamma-band activity and synchronization in human sensorimotor cortex. J Neurosci 27:9270-9277. CrossRef Medline

Jokeit H, Makeig S (1994) Different event-related patterns of gamma-band power in brain waves of fast- and slow-reacting subjects. Proc Natl Acad Sci U S A 91:6339-6343. CrossRef Medline

Kaiser J, Rahm B, Lutzenberger W (2009) Temporal dynamics of stimulusspecific gamma-band activity components during auditory short-term memory. Neuroimage 44:257-264. CrossRef Medline

Koelewijn L, Dumont JR, Muthukumaraswamy SD, Rich AN, Singh KD (2011) Induced and evoked neural correlates of orientation selectivity in human visual cortex. Neuroimage 54:2983-2993. CrossRef Medline

Lachaux JP, Fonlupt P, Kahane P, Minotti L, Hoffmann D, Bertrand O, Baciu M (2007) Relationship between task-related gamma oscillations and BOLD signal: new insights from combined fMRI and intracranial EEG. Hum Brain Mapp 28:1368-1375. CrossRef Medline

Langer T, Martus P, Ottensmeier H, Hertzberg H, Beck JD, Meier W (2002) CNS late-effects after ALL therapy in childhood. Part III: neuropsychological performance in long-term survivors of childhood ALL: impairments of concentration, attention, and memory. Med Pediatr Oncol 38: 320-328. CrossRef Medline

Leech R, Sharp DJ (2014) The role of the posterior cingulate cortex in cognition and disease. Brain 137:12-32. CrossRef Medline

Liu AK, Marcus KJ, Fischl B, Grant PE, Poussaint TY, Rivkin MJ, Davis P, Tarbell NJ, Yock TI (2007) Changes in cerebral cortex of children treated for medulloblastoma. Int J Radiat Oncol Biol Phys 68:992-998. CrossRef Medline

Lutzenberger W, Ripper B, Busse L, Birbaumer N, Kaiser J (2002) Dynamics of gamma-band activity during an audiospatial working memory task in humans. J Neurosci 22:5630-5638. Medline

Mabbott DJ, Noseworthy MD, Bouffet E, Rockel C, Laughlin S (2006) Dif- 
fusion tensor imaging of white matter after cranial radiation in children for medulloblastoma: correlation with IQ. Neuro Oncol 8:244-252. CrossRef Medline

Mabbott DJ, Penkman L, Witol A, Strother D, Bouffet E (2008) Core neurocognitive functions in children treated for posterior fossa tumors. Neuropsychology 22:159-168. CrossRef Medline

Mabbott DJ, Snyder JJ, Penkman L, Witol A (2009) The effects of treatment for posterior fossa brain tumors on selective attention. J Int Neuropsychol Soc 15:205-216. CrossRef Medline

Mahone EM, Prahme MC, Ruble K, Mostofsky SH, Schwartz CL (2007) Motor and perceptual timing deficits among survivors of childhood leukemia. J Pediatr Psychol 32:918-925. CrossRef Medline

Mainy N, Kahane P, Minotti L, Hoffmann D, Bertrand O, Lachaux JP (2007) Neural correlates of consolidation in working memory. Hum Brain Mapp 28:183-193. CrossRef Medline

Martinovic J, Gruber T, Müller MM (2007) Induced gamma band responses predict recognition delays during object identification. J Cogn Neurosci 19:921-934. CrossRef Medline

Mazziotta J, Toga A, Evans A, Fox P, Lancaster J, Zilles K, Woods R, Paus T, Simpson G, Pike B, Holmes C, Collins L, Thompson P, MacDonald D, Iacoboni M, Schormann T, Amunts K, Palomero-Gallagher N, Geyer S, Parsons L, et al (2001) A probabilistic atlas and reference system for the human brain: International Consortium for Brain Mapping (ICBM). Philos Trans R Soc Lond B Biol Sci 356:1293-1322. CrossRef Medline

Merchant TE, Kiehna EN, Li C, Xiong X, Mulhern RK (2005) Radiation dosimetry predicts IQ after conformal radiation therapy in pediatric patients with localized ependymoma. Int J Radiat Oncol Biol Phys 63:15461554. CrossRef Medline

Merchant TE, Conklin HM, Wu S, Lustig RH, Xiong X (2009) Late effects of conformal radiation therapy for pediatric patients with low-grade glioma: prospective evaluation of cognitive, endocrine, and hearing deficits. J Clin Oncol 27:3691-3697. CrossRef Medline

Miltner WH, Braun C, Arnold M, Witte H, Taub E (1999) Coherence of gamma-band EEG activity as a basis for associative learning. Nature 397: 434-436. CrossRef Medline

Monje ML, Mizumatsu S, Fike JR, Palmer TD (2002) Irradiation induces neural precursor-cell dysfunction. Nat Med 8:955-962. CrossRef Medline

Mulhern RK, Reddick WE, Palmer SL, Glass JO, Elkin TD, Kun LE, Taylor J, Langston J, Gajjar A (1999) Neurocognitive deficits in medulloblastoma survivors and white matter loss. Ann Neurol 46:834-841. CrossRef Medline

Müller MM, Gruber T, Keil A (2000) Modulation of induced gamma band activity in the human EEG by attention and visual information processing. Int J Psychophysiol 38:283-299. CrossRef Medline

Padovani L, André N, Constine LS, Muracciole X (2012) Neurocognitive function after radiotherapy for paediatric brain tumours. Nat Rev Neurol 8:578-588. CrossRef Medline

Ray S, Niebur E, Hsiao SS, Sinai A, Crone NE (2008) High-frequency gamma activity $(80-150 \mathrm{~Hz})$ is increased in human cortex during selective attention. Clin Neurophysiol 119:116-133. CrossRef Medline

Reddick WE, White HA, Glass JO, Wheeler GC, Thompson SJ, Gajjar A, Leigh L, Mulhern RK (2003) Developmental model relating white matter volume to neurocognitive deficits in pediatric brain tumor survivors. Cancer 97:2512-2519. CrossRef Medline

Riggs L, Bouffet E, Laughlin S, Laperriere N, Liu F, Skocic J, Scantlebury N, Wang F, Schoenhoff NJ, Strother D, Hukin J, Fryer C, McConnell D, Mabbott DJ (2014) Changes to memory structures in children treated for posterior fossa tumors. J Int Neuropsychol Soc 20:168-180. CrossRef Medline

Robinson S, Vrba J (1999) Functional neuroimaging by synthetic aperture magnetometry (SAM). Sendai, Japan: Tohku UP.

Roy K, Murtie JC, El-Khodor BF, Edgar N, Sardi SP, Hooks BM, Benoit-
Marand M, Chen C, Moore H, O’Donnell P, Brunner D, Corfas G (2007) Loss of erbB signaling in oligodendrocytes alters myelin and dopaminergic function, a potential mechanism for neuropsychiatric disorders. Proc Natl Acad Sci U S A 104:8131-8136. CrossRef Medline

Schadow J, Dettler N, Paramei GV, Lenz D, Fründ I, Sabel BA, Herrmann CS (2009) Impairments of Gestalt perception in the intact hemifield of hemianopic patients are reflected in gamma-band EEG activity. Neuropsychologia 47:556-568. CrossRef Medline

Schatz J, Craft S, Koby M, DeBaun MR (2000a) A lesion analysis of visual orienting performance in children with cerebral vascular injury. Dev Neuropsychol 17:49-61. CrossRef Medline

Schatz J, Kramer JH, Ablin A, Matthay KK (2000b) Processing speed, working memory, and IQ: a developmental model of cognitive deficits following cranial radiation therapy. Neuropsychology 14:189-200. CrossRef Medline

Snijders TM, Milivojevic B, Kemner C (2013) Atypical excitation-inhibition balance in autism captured by the gamma response to contextual modulation. Neuroimage Clin 3:65-72. CrossRef Medline

Spiegler BJ, Bouffet E, Greenberg ML, Rutka JT, Mabbott DJ (2004) Change in neurocognitive functioning after treatment with cranial radiation in childhood. J Clin Oncol 22:706-713. CrossRef Medline

Sun L, Grützner C, Bölte S, Wibral M, Tozman T, Schlitt S, Poustka F, Singer W, Freitag CM, Uhlhaas PJ (2012) Impaired gamma-band activity during perceptual organization in adults with autism spectrum disorders: evidence for dysfunctional network activity in frontal-posterior cortices. J Neurosci 32:9563-9573. CrossRef Medline

Sun L, Castellanos N, Grützner C, Koethe D, Rivolta D, Wibral M, Kranaster L, Singer W, Leweke MF, Uhlhaas PJ (2013) Evidence for dysregulated high-frequency oscillations during sensory processing in medicationnaive, first episode schizophrenia. Schizophr Res 150:519-525. CrossRef Medline

Tallon-Baudry C, Bertrand O, Peronnet F, Pernier J (1998) Induced gamma-band activity during the delay of a visual short-term memory task in humans. J Neurosci 18:4244-4254. Medline

Taylor AM (2012) Neuropsychological evaluation and management of sport-related concussion. Curr Opin Pediatr 24:717-723. CrossRef Medline

Todd RM, Taylor MJ, Robertson A, Cassel DB, Doesberg SM, Lee DH, Shek PN, Pang EW (2014) Temporal-spatial neural activation patterns linked to perceptual encoding of emotional salience. PLoS One 9:e93753. CrossRef Medline

Uberall MA, Hertzberg H, Meier W, Langer T, Beck JD, Wenzel D (1996) Visual-evoked potentials in long-term survivors of acute lymphoblastic leukemia in childhood. The German Late Effects Working Group. Neuropediatrics 27:194-196. CrossRef Medline

Waldert S, Preissl H, Demandt E, Braun C, Birbaumer N, Aertsen A, Mehring C (2008) Hand movement direction decoded from MEG and EEG. J Neurosci 28:1000-1008. CrossRef Medline

Wechsler D (2004) The Wechsler intelligence scale for children, Ed 4. London: Pearson Assessment.

Wilke M, Schmithorst VJ, Holland SK (2002) Assessment of spatial normalization of whole-brain magnetic resonance images in children. Hum Brain Mapp 17:48-60. CrossRef Medline

Winick N (2011) Neurocognitive outcome in survivors of pediatric cancer. Curr Opin Pediatr 23:27-33. CrossRef Medline

Xiang J, Degrauw X, Korman AM, Allen JR, O’Brien HL, Kabbouche MA, Powers SW, Hershey AD (2013) Neuromagnetic abnormality of motor cortical activation and phases of headache attacks in childhood migraine. PLoS One 8:e83669. CrossRef Medline

Zou P, Mulhern RK, Butler RW, Li CS, Langston JW, Ogg RJ (2005) BOLD responses to visual stimulation in survivors of childhood cancer. Neuroimage 24:61-69. CrossRef Medline 